\title{
Editorial - the changing face of ALT-J
}

\section{Introduction}

The $A L T-J$ conference special issue is usually introduced by an editorial by the organizers of the conference. This year, we are breaking with tradition by including an article which discusses the way in which the conference has changed over the last seven years. Encouragingly it suggests that there is evidence that learning technology is maturing as a research area, and becoming more firmly embedded into tertiary institutions.

This year's conference was held at UMIST in Manchester. It was the largest conference to date - a credit to Peter Hicks, Clive Young, Ben Plumpton and the other conference organizers. The papers selected for this issue reflect the conference theme of policy, practice and partnership and range from discussions of the development of strategic alliances and organizational issues (Crock et al., McMurray) through to specific institutional studies (Boyle and Cook, Bhalerao and Ward, Slaouti, and French et al.). The issue begins with an example of best practice from one of this year's keynote speakers, Betty Collis, a paper which reflects much of the findings described in Gabriel Jacobs's editorial piece below, by providing an illustration of one institution's large-scale implementation of innovative uses of learning technology.

\section{Gräinne Conole}

\section{Editorial reflection - the changing face of ALT-C}

In selecting past papers from ALT-J for The Changing Face of Learning Technology (Squires, Conole and Jacobs, 2000), my co-editors and I recognized that journal papers alone, and from a single source, would unavoidably present a skewed perspective. Here is a 
different, if equally imperfect but (if I may say so) equally interesting, picture: a survey of the published abstracts (papers, workshops and so forth) from each ALt conference from the first, Alt-C 94, to Alt-C 2000, to which this issue of $A L T-J$ is devoted.

\section{Classification method}

An analysis of conference abstracts involves a measure of subjectivity. The ALT-C abstracts offer a number of different potential divisions, a distinctive one being the focal point of this editorial, namely that between discipline-specific contributions and those of a general nature. Yet contributions which demand to be classified as being of universal interest may well have a subject-specific content. Conversely, many contributions which should clearly be classified as specific to a discipline deal with issues which are applicable well beyond the confines of that discipline. In examining each abstract for discipline-specific content (often belied by the title of the presentation), I had to make a judgement in several doubtful cases.

A large number of abstracts patently fell into the general category, there being little or no mention of any specific academic discipline (typically, contributions concerned with transferable skills, evaluation, computer-aided assessment, learning theory, learning resources, institutional viewpoints, lifelong learning, staff development, support for disabled students, and so on). I also classified a contribution as general if examples were taken from more than two disciplines, unless there were compelling reasons not to do so (as in direct comparisons). If examples were taken from only one or two disciplines (in the vast majority of cases, one), I again made a judgement with respect to the importance of the discipline(s) treated as against that of the 'universality' of the abstract.

Next, I divided the presentations into discipline categories, as follows:

- Art and Design (including Architecture);

- Business Management and Economics;

- Engineering (including Civil, Mechanical, Chemical, Materials);

- Mathematics and Statistics;

- Computer Science (including Information Science if not aimed merely at providing transferable IT skills);

- Physical Sciences (including Meteorology, Environmental Sciences);

- Earth Sciences (including Geography, Geology, Energy Studies);

- Life Sciences;

- Health Sciences (including Medicine, Nursing and Midwifery, Pharmacology, Dentistry, Veterinary Studies);

- Social Sciences (including Psychology);

- Humanities (including History, Textual Studies, Music);

- Modern Languages; 
- Miscellaneous (incorporating, for example, Teacher Education, Library Studies, General Science, Law).

The decision to categorize disciplines in this way was based on the major patterns revealed in the data. For example, Textual Studies and Music did not warrant separate categories since such categories would have contained very few abstracts; these two disciplines were therefore included in the Humanities category. On the other hand, the number of presentations specifically dealing with Modern Languages justified a category separate from Humanities. With one exception (Teacher Education, discussed in the conclusion below), disciplines which yielded for all years fewer than five presentations in total, and which did not naturally fall into another category, were classed as Miscellaneous disciplinespecific. However, Architecture, Environmental Sciences, Energy Studies and Psychologynone of which quite produced sufficient numbers of presentations to warrant separate categories - for the most part were included respectively in Art and Design, Physical Sciences, Earth Sciences and Social Sciences. Where two distinct disciplines were treated in the same presentation, and where their importance justified a discipline-specific categorization, each discipline was added to the appropriate category total.

All the above, and the fact that the fragmentation into categories has inevitably entailed working with comparatively small numbers, has to be borne in mind when it comes to assessing both the value of the results and the conclusions I have tentatively drawn. I believe, nevertheless, that the results are revealing, and the conclusions broadly valid.

\section{Results of the analysis}

The total numbers of presentations for each year are shown in Figure 1. It can be seen that during the first three years, ALT conferences encompassed a rising number of contributions, a number which fell away in 1997 and 1998, gradually to rise again for the last two years. Many factors affect the number of presentations given at a conference. The apparent dwindling of interest in 1997 and 1998 may owe much to the approach of

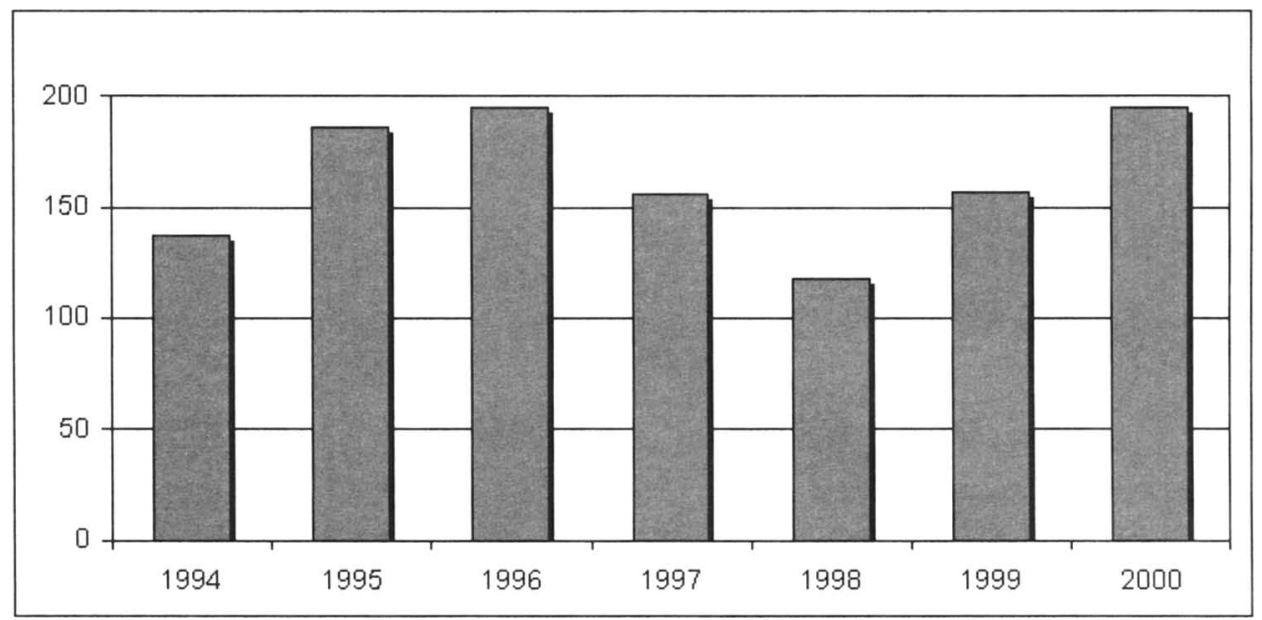

Figure 1: Total number of presentations. 
organizing committees. I am assured by ALT that feedback from every conference criticizes the degree of parallelism adopted, and that organizers have reacted in different ways, either ignoring the feedback, or shortening the presentation slots, or lengthening the conference, or combining presentations into single sessions, or accepting fewer proposals. I am also assured that there has been a year-on-year increase in the number of proposals received. Whatever the case may be, I would speculate that the rising shape of the curve at the righthand side of Figure 1 is partly related to the effect of the Dearing Report's emphasis on C\&IT (an acronym first seen in its pages).

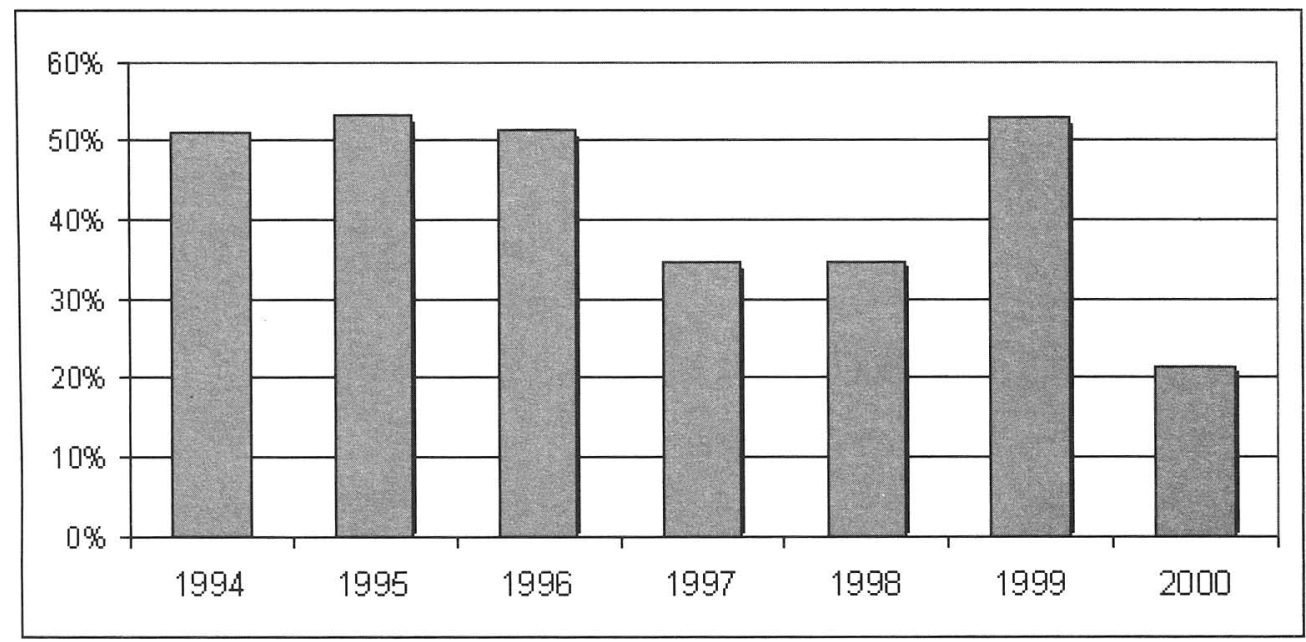

Figure 2: Percentage of discipline-specific presentations.

Figure 2 depicts, for each year, discipline-specific presentations as a percentage of the total of presentations. The bars show that for the first three years about half the presentations were discipline-specific. Then a drop once again distinguishes the years 1997 and 1998, to return to around the 50 per cent mark in 1999, while the year 2000 sees a striking fall to less than a quarter of the total. These results are particularly indicative when one takes into account that the figure for 1999 is a blip. In that year, given the particular affiliations of the conference organizers, there was strong encouragement for CTI centres to run discipline strands. If one takes out this exceptional year, the trend is clear: a steady move towards fewer discipline-specific presentations. When ALT began, most presenters at the conferences were academics dabbling in learning technology, whereas the last few years have seen a dramatic increase in staff employed explicitly to promote and support it within their institutions; by and large, these people do not have a discipline affiliation. It would appear that ALT-C has seen a consequent change in the professional status of presenters (it is not possible to quantify such a statement from the evidence of conference abstracts, but I am told by AlT officials that this is indeed their impression). A reasonable conclusion would be that the move away from discipline-based presentations is, at least to some degree, a reflection of the increasing professionalization of learning technology, disciplinespecific presentations being, on the whole, the natural domain of the enthusiastic amateur, and widely applicable presentations that of the professional. 
Again leaving aside the unusual ALT-C 1999, the fall in discipline-specific presentations between 1997 and 2000 was also no doubt accelerated by the relatively sudden allpervasiveness of the Internet. The Web has played a more important role than any other factor in helping learning technology to gain general acceptance. And it was in 1998 and 1999 that the Web truly began to influence strategic thinking throughout tertiary and higher education, not just among certain enthusiastic institutions as it had done until then. Why should the enveloping nature of the Internet have affected the number of disciplinespecific presentations at a learning-technology conference? Perhaps because here was (and still is) a new field with as yet few general ground rules. Of the 195 presentations at AlT-C 2000 , well over half dealt directly with online learning, and the abstracts of many of the remaining presentations assume delivery via the Web. This contrasts with the first three years of AlT conferences, during which period the main delivery media were the CD-ROM and the diskette, both of which had been firmly established for some time (by 1996, CDROM drives were supplied as standard with most desktop computers). On average for those first three years, fewer than 20 per cent of presentations were directly linked to online or networked learning, and for the first ALT conference the figure was a mere 11 per cent. It would seem that the rapid penetration of the Internet into academic consciousness provoked a flurry of contributions focusing on guidelines for its use.

\section{Results for individual discipline categories}

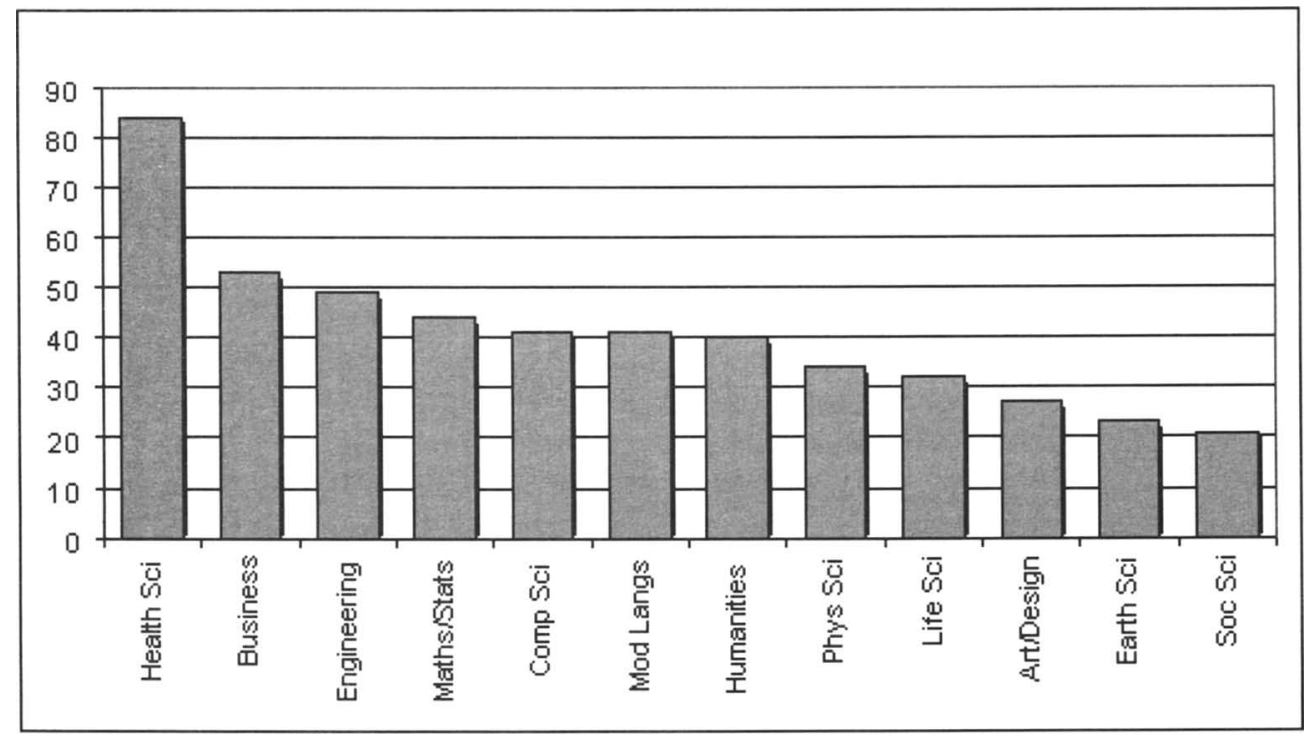

Figure 3: Overall totals of discipline-specific presentations.

Figure 3 shows the total number of presentations in each category over the seven-year period. It can be seen that Health Sciences overshadows all other categories, generating over twice as many presentations as each of Computer Science, Modern Languages and 
Humanities, coming close to three times as many as Physical Sciences and Life Sciences, and more than three times as many as Art and Design, Earth Sciences and Social Sciences. The fact that, in the hierarchy below Computer Science, there is a mix of discipline categories in which one might expect computer expertise or otherwise, indicates that such expected expertise or the lack of it has not had an obvious overall effect. However, there may be a correlation here between funding bands and disciplines. Where the cost of teaching is particularly high, there is a significant amount to be saved from not carrying out a traditional activity, for example by substituting dry labs for wet labs, although this potential saving does not explain the comparatively poor showing of, say, Earth Sciences (see below).

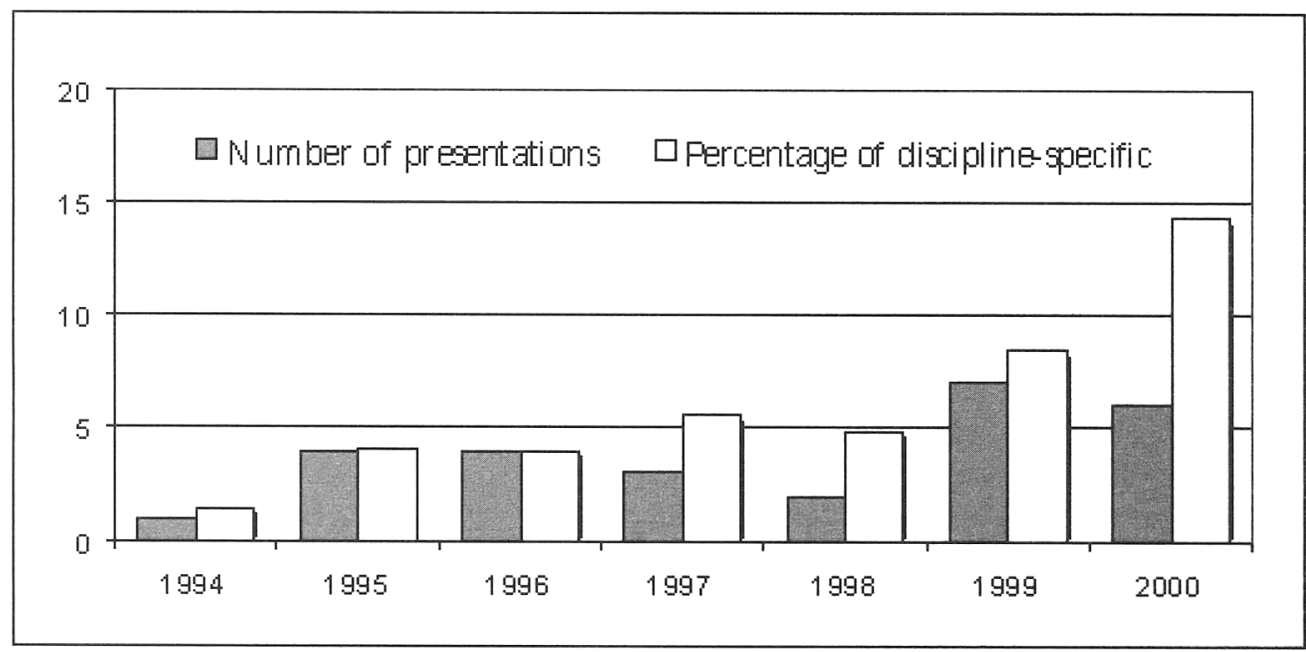

Figure 4: Data for Art and Design.

Other possible reasons for this situation are mentioned in relation to Figures 4 to 15 which depict the results for the discipline categories for each year. For each category, a set of bars are graphed for the number of presentations in the category in question, with an adjacent set to their right for that number calculated as a percentage of all discipline-specific presentations (for convenience and purposes of comparison, in each case the $\mathrm{Y}$ axis in this way acts as a measure of both absolute numbers and percentages).

\section{Art and Design}

After a slow start in 1994, the curve representing the number of presentations for Art and Design (Figure 4) follows the general pattern of a fall in 1997 and 1998, but reveals a more or less steady rise in percentage terms throughout the seven-year period, with a noticeable rise in 2000. I would imagine that this is in part related to the escalating graphics capabilities of desktop computers. As the processing power, physical storage, randomaccess memory and graphics sub-systems of commonly available hardware have continued to catch up with the potential of graphics software, display control has seen considerable advances, and design, painting and drawing programs have become far more usable for non-technical people. In addition, for the last few years students taking Art and Design 


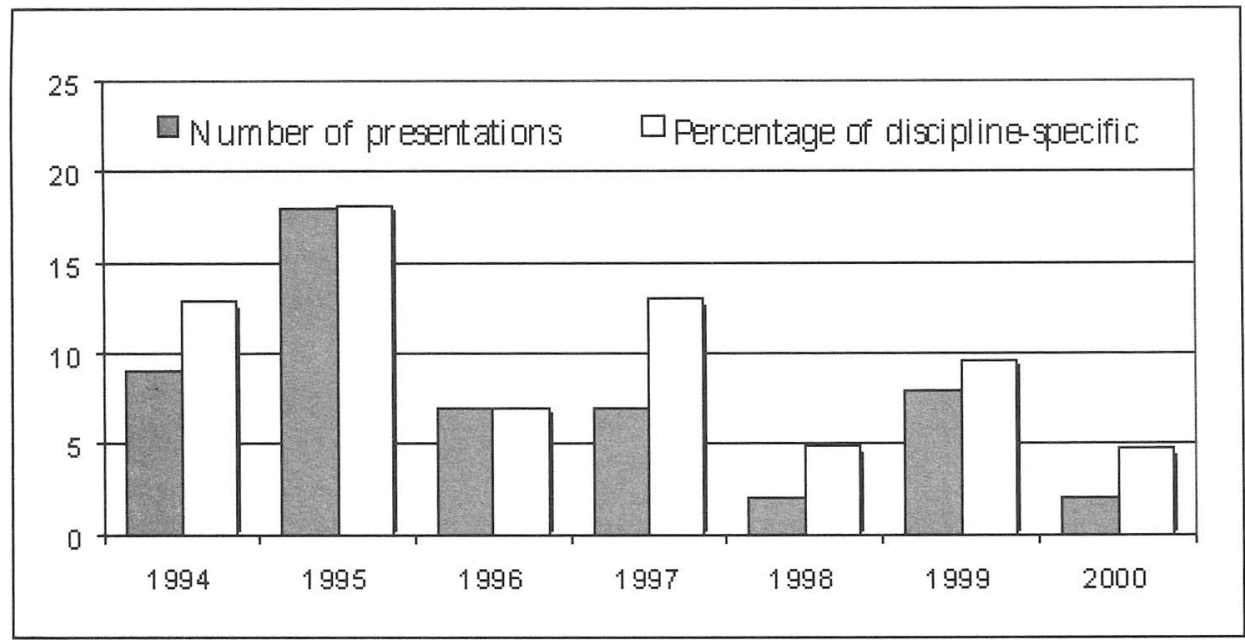

Figure 5: Data for Business Management and Economics.

and related subjects have been expected to make increasing use of computers, something which must have had a knock-on effect for the potential of learning technology in this discipline category.

\section{Business Management and Economics}

As can be seen from Figure 5, Business Management and Economics saw a substantial boost in 1995. This was mostly due to the large number of presentations in those years focused on WinEcon, one of the most successful products to emerge from the TLTP programme of the time (even marketed commercially). The high figures for 1994 and 1995 may once again be due to the growing importance of graphic displays in business computing, and especially the graphing capabilities of Excel, which by this time had all but ousted its direct competition. The figure for 1998 follows the fall in the total of presentations, but somewhat exaggeratedly so. Perhaps by 1997/8 there was little more that could be said about WinEcon: the package was commercially moribund and (though my evidence is anecdotal) conceivably represented a failure which had a general depressing effect on learning-technology activity in Economics. The apparent return to 'normal' activity in 1999 indicates a revival of interest, although it is worth mentioning that in this particular year Business Management is more responsible than Economics for the resulting figures. The fact of only two presentations in this category in 2000 is disappointing, but it may be that it should be taken together with the strong interest shown at ALT-C 2000 in training for small businesses (see the conclusion below) across various subject-areas not necessarily directly related to Business Management as a discipline. The decline is nevertheless surprising, especially given the dominance of the online education market by MBA courses.

\section{Engineering}

With Engineering (Figure 6), after three good years 1997 sees something of a decline (even taking into account the general fall in the number of presentations in that year and 1998). It 


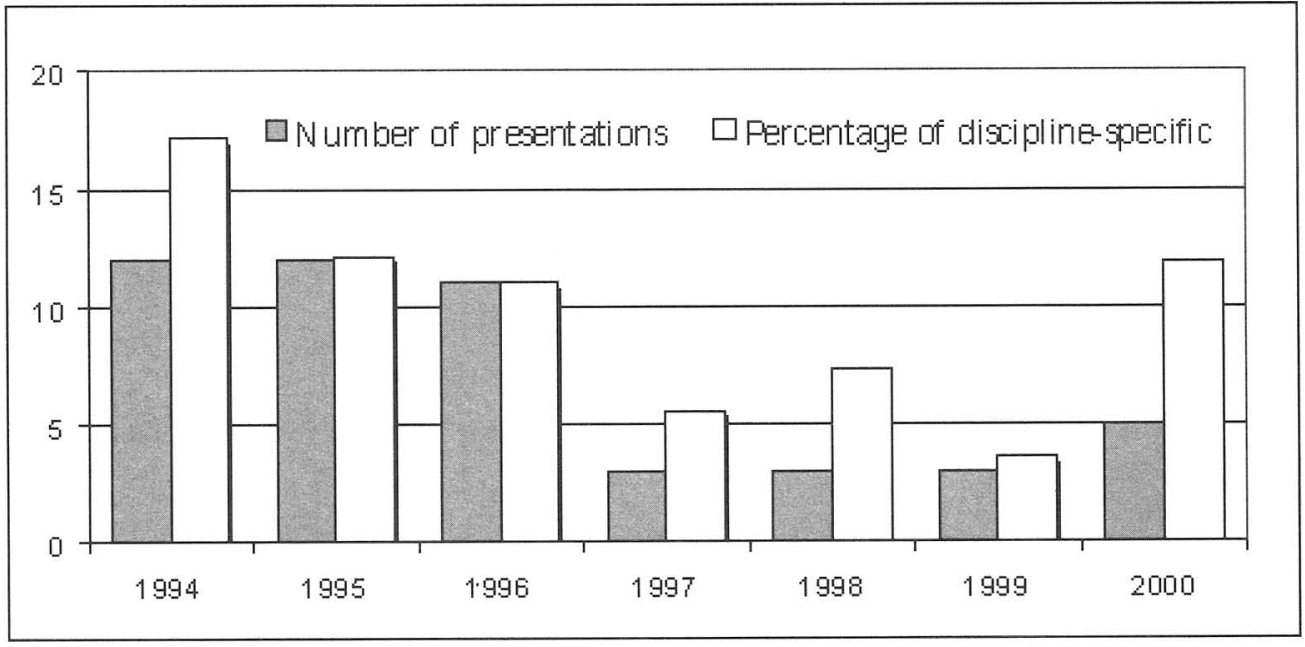

Figure 6: Doto for Engineering.

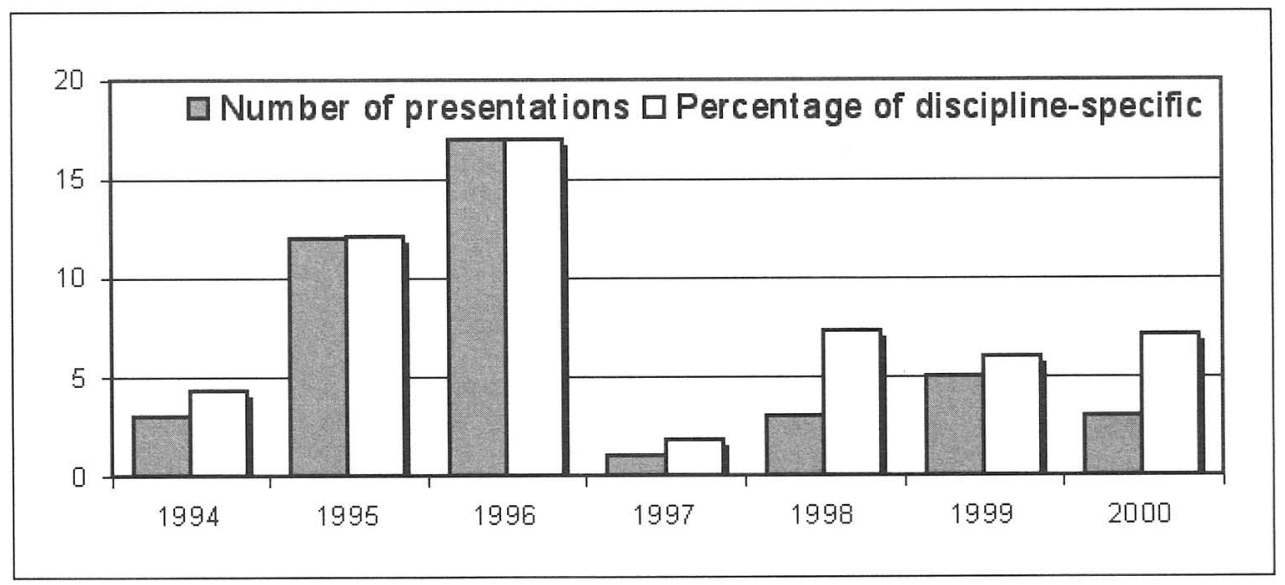

Figure 7: Data for Mathematics and Statistics.

looks as if, pro rata, 2000 might represent the beginning of a reversal of Engineering fortunes. Is this related, once more, to ever-increasing availability of graphics power? Whatever the answer to that question, Jonathan Darby, who at one time headed up the CTI support network, is convinced that in disciplines where the use of computers is pervasive in research, academics are less inclined to recognize that they could benefit from discussion about their use in teaching. As a result, innovative CAL applications in the 'computerate' disciplines may have been less forthcoming than the nature of those disciplines would imply.

\section{Mathematics and Statistics}

A picture comparable with that of Engineering emerges for Mathematics and Statistics (Figure 7). Here, however, there may be a less tentative explanation, that of the growing 


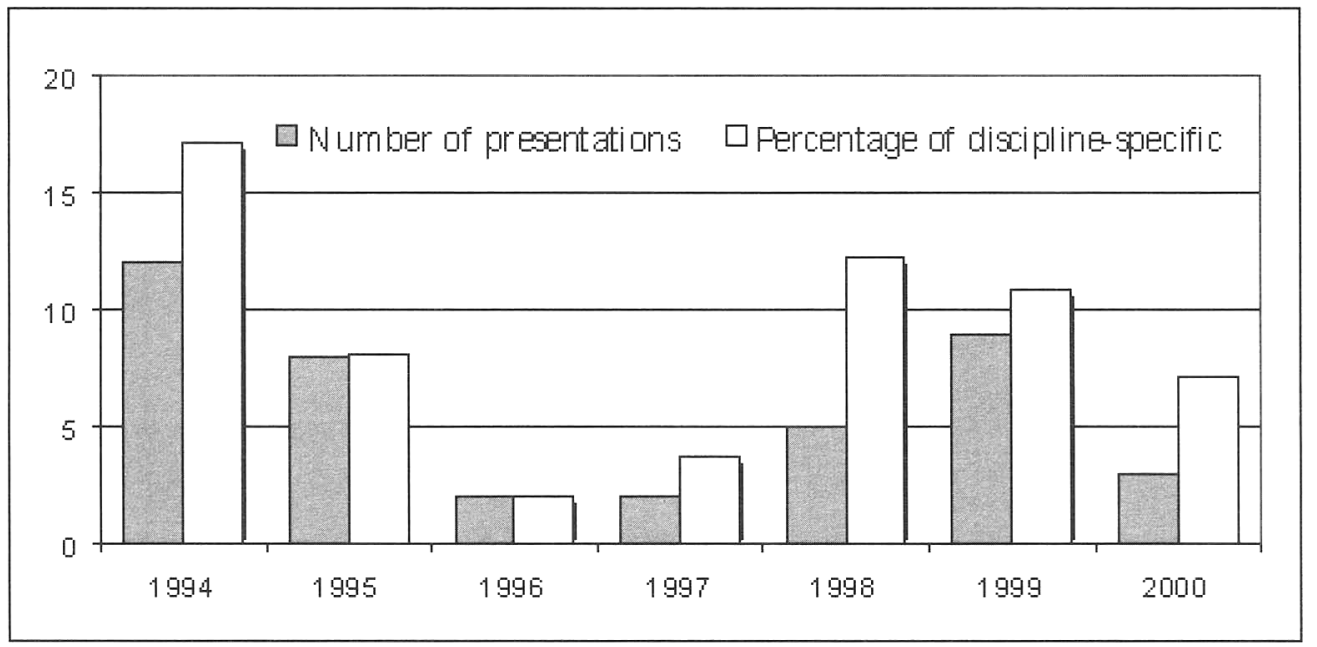

Figure 8: Data for Computer Science.

importance of Mathwise - the most lavishly funded TLTP project after Modern Languages which reached its peak in 1996. While not all presentations in that year were concerned with it, it probably had an effect outside its own confines. The sudden fall in 1997, with interest plummeting in Mathwise, could be another example of the 'WinEcon effect' discussed above. Since 1997, in any event, the discipline category appears to be on the road to recovery.

\section{Computer Science}

Computer Science presents a different but equally remarkable set of results (Figure 8), starting excellently in 1994, declining between then and 1996/7, then rising again (in terms of numbers) until the fall in 2000. The early strong showing no doubt reflects the perception at the time of the frontiers of learning technology being primarily technical (for which computer scientists, of course, had the answers). Then, as attention shifted to pedagogy and social aspects, it could be that there was less to engage the Computer Science community. The content of the abstracts published between 1998 and 1999 confirms, however, that networking, not surprisingly (and once again) first focused on by computer scientists, was responsible for the subsequent recovery. Does the 2000 figure indicate history repeating itself, as Internet technology becomes everyone's bread and butter?

\section{Physical Sciences}

Figure 9 shows Physical Sciences having maintained a fairly steady pace, if a slightly discouraging one, given that by rights they should lend themselves well to learning technology; simulations, for example, would appear perfectly to fit the bill. But if there is some weight in the comment made above with respect to Engineering - that there seems to be less innovation in CAL in the disciplines where computers are extensively used in research - the same probably applies here.

\section{Earth Sciences}

Since there are so few presentations in the Earth Sciences category, the results shown in Figure 10 may be due mostly to chance or extraneous factors. Even so, the results are 


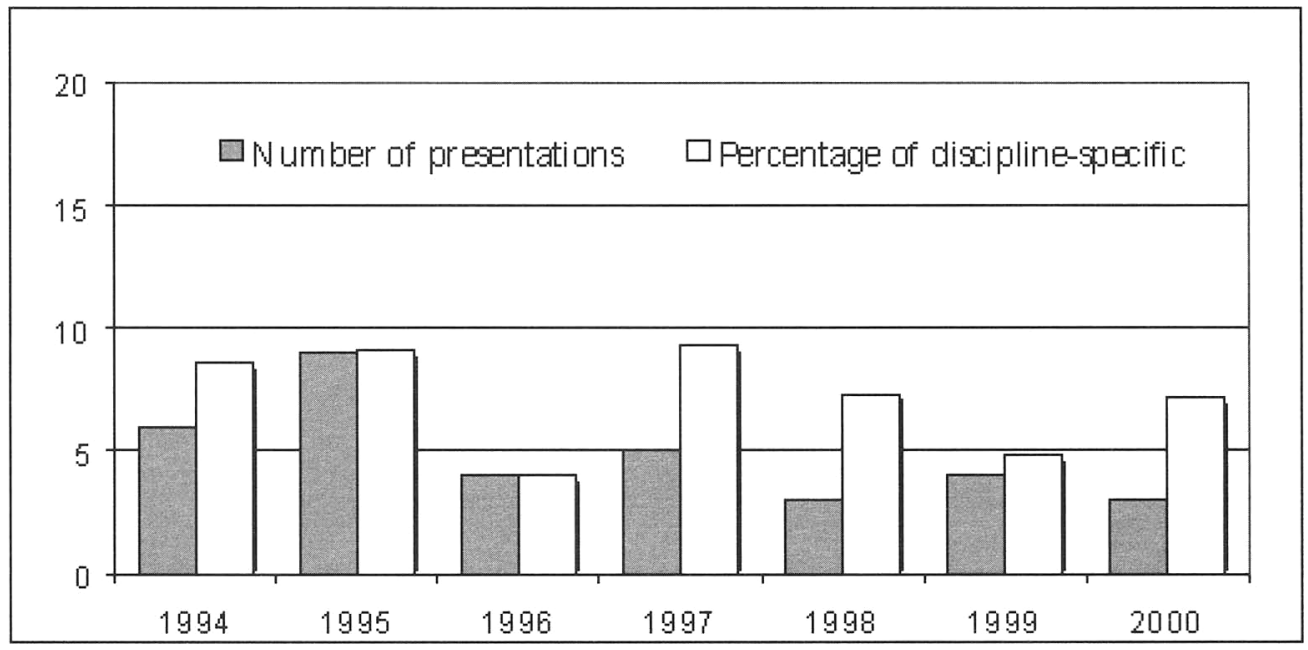

Figure 9: Data for Physical Sciences.

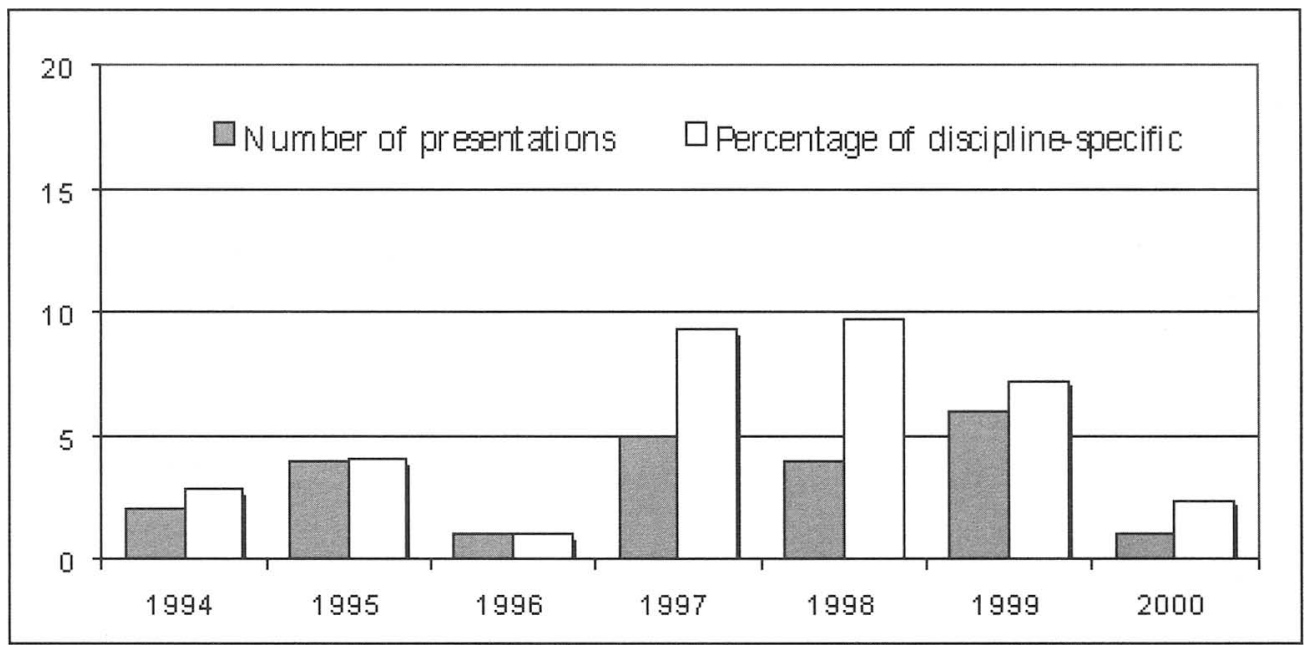

Figure 10: Data for Earth Sciences.

gloomy: Earth Sciences have been very poorly represented at ALT conferences. I can offer no evident explanation for this state of affairs.

\section{Life Sciences}

Life Sciences (once more, for me, inexplicably, given the nature of the category and the large numbers of students attracted to subjects such as Biology), can hardly be said to present a much rosier picture (Figure 11). The two curves fluctuate somewhat, but the most promising year (1996) is followed two years later by a significant fall, and with hardly a startling recovery in 1999 and 2000. 


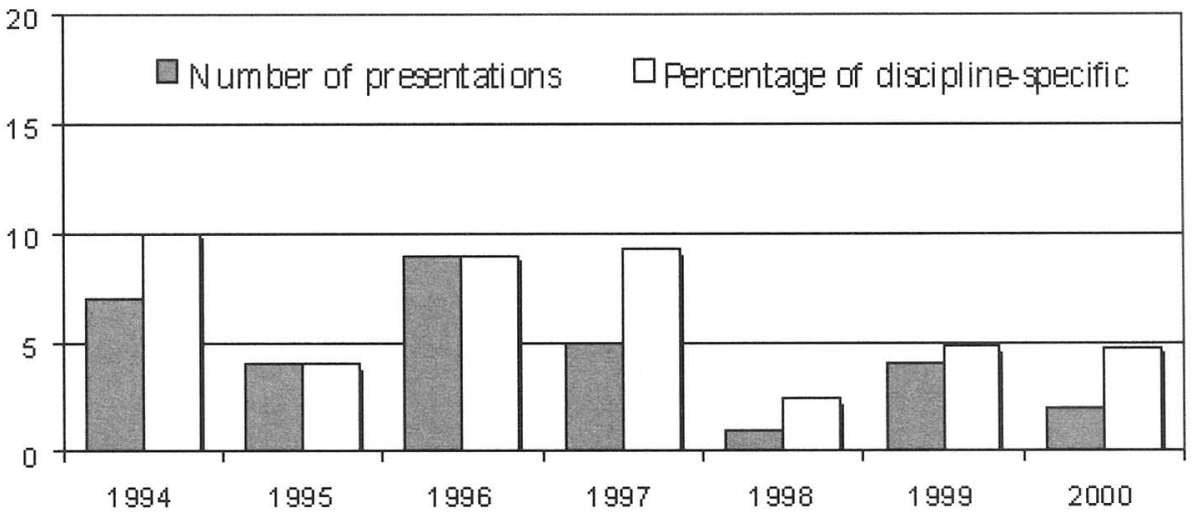

Figure 11: Dato for Life Sciences.

\section{Health Sciences}

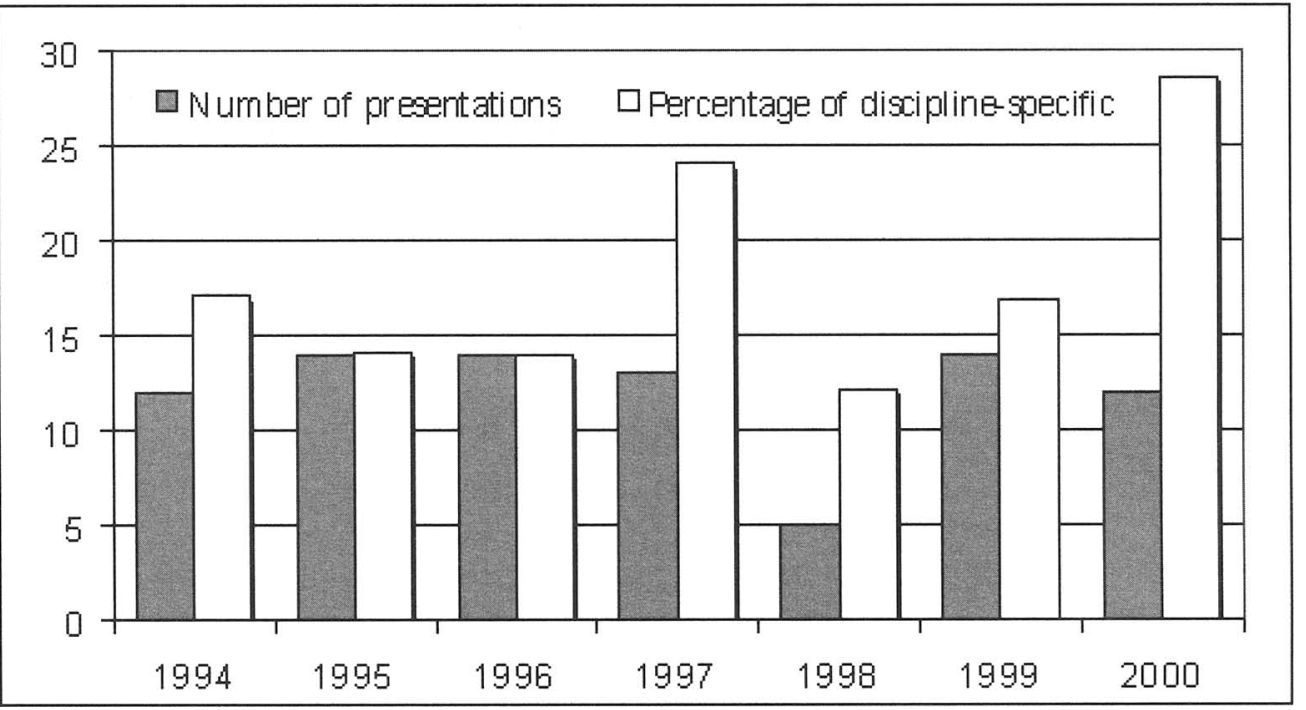

Figure 12: Data for Health Sciences.

In contrast, as can be seen from Figure 12, each year with the exception of 1998 the Health Sciences category has attracted a significant number of presentations. Even at its lowest point in 1998, it still accounted for about 12 per cent of discipline-specific presentations. High points were 1997, where the figure rose to almost a quarter, and 2000 where it completely dominated the picture. One cannot readily account for such a high proportion 
of Health Science presentations in terms of the increasing power and usability of desktop computers, since, disregarding the fall in 1998, the intensity in this case remains remarkably constant throughout the seven-year period. It could be that the very large numbers of students characteristically to be found on medical-related courses, and the comparative scarcity of teaching staff, have together played important roles in the maintenance of a high level of interest in learning technology within this category. Equally possible is the closeness of health-science education to practice (there is more on-the-job training than in most other fields). But there again, the same principles might broadly apply to other categories, including Teacher Training which did not even justify its own category if one discounts the year 2000 (see the conclusion, below). Part of the reason may lie in the high dependency on technology in medicine, and perhaps in particular on the fact that computers make it possible to carry out and demonstrate experiments that would otherwise be costly and/or difficult to do, and even ethically suspect.

The fact remains that Health Sciences have been unquestionably the healthiest discipline component at ALT conferences, and, if there is a correlation between the demonstrated interest of those teachers in the field involved in using learning technology and its uptake in institutions (as there surely is), this is something which ought to be investigated in order to determine whether or not there are lessons to be learned in other disciplines.

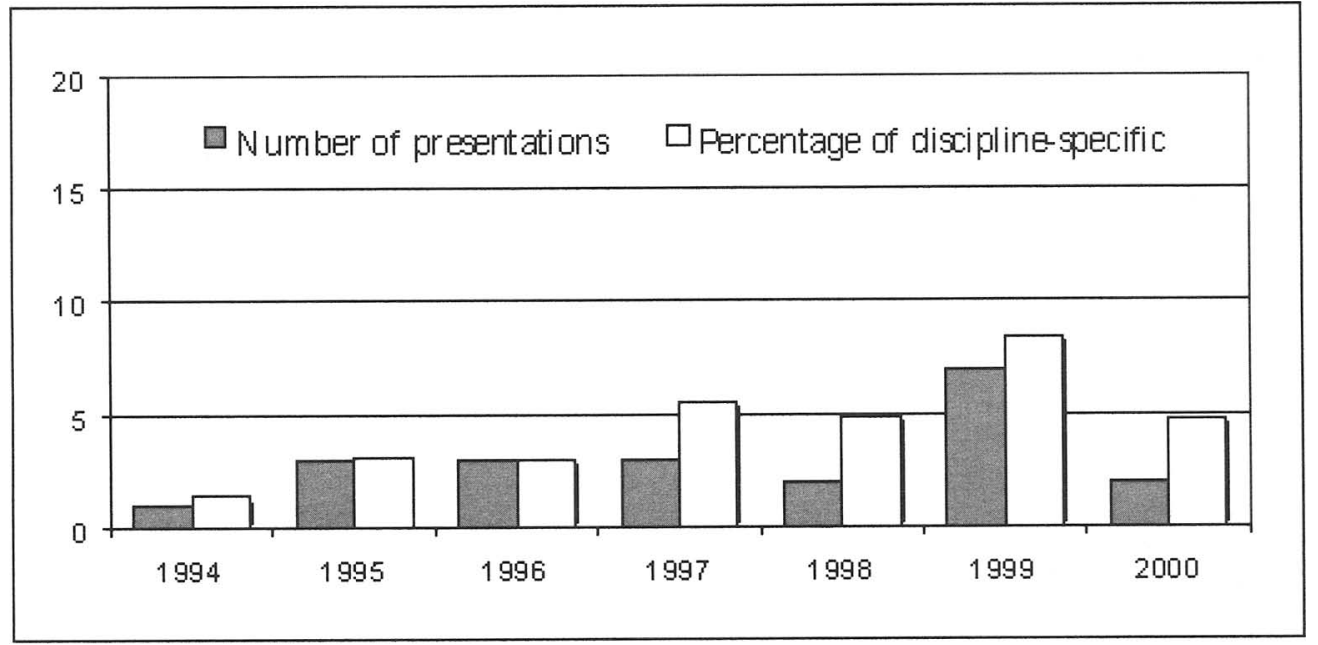

Figure 13: Data for Social Sciences.

\section{Social Sciences}

Conversely, Social Sciences perform poorly (Figure 13), coming bottom in the league table (Figure 3). Why the Social Sciences (including Psychology, so popular with students) should show results weaker than, say, the Humanities (see immediately below), is something of a mystery, although part of the explanation certainly lies in the thriving Computers in Psychology annual conference: it undoubtedly attracts proposals which might otherwise be submitted to Alr-C. 


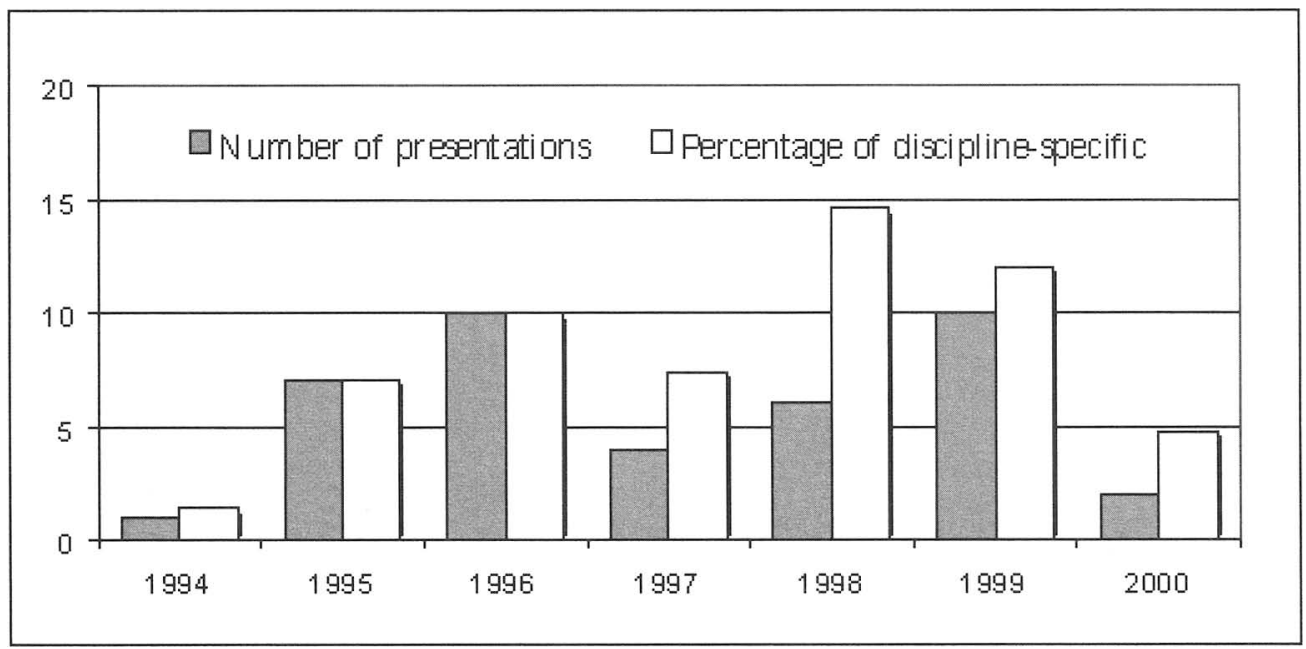

Figure 14: Data for Humanities.

\section{Humanities}

When Alt was founded in 1993, it was thought by many that the sciences would dictate the development of learning technology because of the scientific nature of technology itself. Yet, since then, many within the Humanities have adopted it as a teaching (and research) facility, and this is evidenced by the data in Figure 14. After a weak start in 1994, the numbers are more than respectable (nearly 15 per cent of discipline-specific presentations in the meagre year 1998). The year 2000 , however, has seen a fall which is disquieting if it is not due to some exceptional factor; disquieting if only because, if learning technology is to become generally accepted, it must solidly encompass those disciplines in which academic staff are not traditionally technologically orientated.

\section{Modern Languages}

Much the same could be said of Modern Languages (Figure 15), though with that significant peak in 1996, surely the result of efforts put in by the relevant CTI Centre and by a number of conference organizers at about that time in promoting CALL (Computer Assisted Language Learning). The low figure for the following year, even taking into account its relatively overall paucity, may be in part the consequence of a reaction to what I think must be seen as the over-enthusiasm of the previous year. The zeal for CALL products was to be tempered with the realization that user-expectations did not fully match what the available software could offer, natural language being notoriously difficult to computerize in whatever way one cares to mention. CALL has continued to attract interest (Figure 15 is evidence enough of that), but it has never regained the exhilarating momentum of four to five years ago. Let us hope that the minimal showing at ALT-C 2000 is not ominous. 


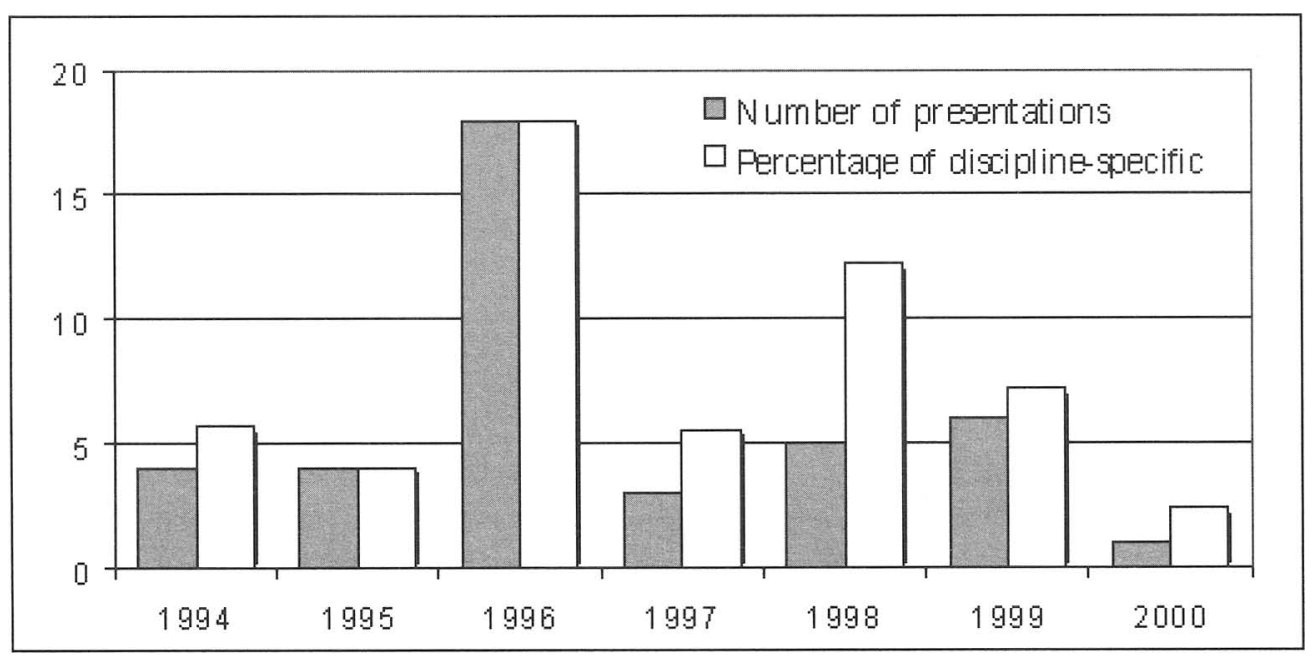

Figure 15: Data for Modern Languages.

\section{Conclusion}

One could point to a number of differences between years with respect to the presentations given at Alt conferences. To take Alt-C 2000 (since it provides the most up-to-date picture), there was an abrupt rise in papers concerned with Teacher Training. For the years preceding 2000, this discipline did not warrant a separate category, but ALT-C 2000 saw four presentations concerned specifically with it. This sudden increase may be the consequence of a number of coincidental factors, but I suspect that it is related to some extent to recent government initiatives to promote ICT literacy among schoolteachers. Again at Alt-C 2000, there was a notable turn towards the provision of ICT training for small businesses. Whereas previous years had seen hardly a mention of them, six presentations at ALT-C 2000 dealt directly with their requirements or their relationship with the education sector. I presume that this change is linked to the increased availability of appropriate European funding, combined with the recent move within ALT fully to embrace further education, and thus vocational training. ALT-C thus appears to be responding rapidly to developments, an encouraging sign even if certain major disciplines are still disappointingly absent or nearly absent (Law is a prime example).

But Alt-C does not exist in a vacuum. Ideally, in order properly to gauge developments in the field of learning technology - and thus to avoid the numerous caveats and hesitations I have been obliged to incorporate in an effort to forestall the criticism of those who would like to see a fully contextualized survey (I include myself) - it would be necessary to compare the results presented here not only with those of other general learningtechnology conferences but also with discipline-specific conferences and a wide range of books and journal papers, something which would represent an undertaking well beyond my intended scope of an unpretentious overview of Alt-C. Nevertheless, Alt-C is certainly one of the UK's leading learning-technology conferences, indeed probably the leader. So I would contend that the results I have presented may justifiably be considered at least indicative. I hope that they will be taken in that light. 


\section{Acknowledgements}

I am grateful to Jonathan Darby, until last year President of ALT, and to my colleague in the University of Wales Swansea, Dr Catherine Rodgers, both of whom kindly agreed to read a draft of this editorial. Many of their comments and suggestions have been incorporated.

\section{Gabriel Jacobs}

\section{Reference}

Squires, D., Conole, G. and Jacobs, G. (2000), The Changing Face of Learning Technology, Cardiff: University of Wales Press. 